\title{
The Effect of Thermal Annealing Processes on Structural and Photoluminescence of Zinc Oxide Thin Film
}

\author{
Huai-Shan Chin and Long-Sun Chao \\ Department of Engineering Science, National Cheng Kung University, 1 University Road, Tainan, Taiwan \\ Correspondence should be addressed to Long-Sun Chao; 1schao@hflow.es.ncku.edu.tw
}

Received 24 September 2013; Revised 28 November 2013; Accepted 29 November 2013

Academic Editor: Hong Seok Lee

Copyright (C) 2013 H.-S. Chin and L.-S. Chao. This is an open access article distributed under the Creative Commons Attribution License, which permits unrestricted use, distribution, and reproduction in any medium, provided the original work is properly cited.

\begin{abstract}
This study used radio frequency sputtering at room temperature to prepare a zinc oxide $(\mathrm{ZnO})$ thin film. After deposition, the thin film was placed in a high-temperature furnace to undergo thermal annealing at different temperatures $\left(300,400,500\right.$, and $\left.600^{\circ} \mathrm{C}\right)$ and for different dwelling times $(15,30,45$, and $60 \mathrm{~min})$. The objective was to explore the effects that the described process had on the thin film's internal structure and luminescence properties. A scanning electron microscope topographic image showed that the size of the $\mathrm{ZnO}$ crystals grew with increases in either the thermal annealing temperature or the dwelling time. However, significant differences in the levels of influence caused by increasing the thermal annealing temperature or dwelling time existed; the thermal annealing temperature had a greater effect on crystal growth when compared to the dwelling time. Furthermore, the crystallization directions of $\mathrm{ZnO}$ (002), (101), (102), and (103) can be clearly observed through an X-ray diffraction analysis, and crystallization strength increased with an increase in the thermal annealing temperature. The photoluminescence measurement spectra showed that ultraviolet (UV) emission intensity increased with increases in thermal annealing temperature and dwelling time. However, when the thermal annealing temperature reached $600^{\circ} \mathrm{C}$ or when the dwelling time reached 60 min, even exhibited a weak green light emission peak.
\end{abstract}

\section{Introduction}

Because the international community has focused on energy conservation and global warming prevention, white lightemitting diodes (LEDs), which are energy-efficient, environmentally friendly, and safe, have become the new light source of the twenty-first century. This phenomenon has created a substantial market opportunity for white LEDs, and they have gradually become a mainstream product in the market. Although high quality manufacturing technology and stable procedural parameters currently exist for white LEDs, high production costs, operational difficulties related to alternating current (AC), and the inability to provide white-light illumination for large areas highlight the application deficiencies of white LEDs. Consequently, the industry targets these deficiencies as directions for improvement. Thick-film dielectric electroluminescence (TDEL) technology, which comprises electroluminescence components, is currently used by research authorities to actively develop white light excitation. The TDEL structure is self-emitting, flat, large, and applicable to AC, and it emits uniform light. Consequently, it can ameliorate white LED application insufficiencies, becoming a new-generation white lighting product. If the TDEL technology can replace a part of the white LED market, its future market potential is limitless.

Electroluminescence is a phenomenon of energy emission where high voltages are applied to electrodes on both sides of a phosphor; subsequently, the phosphor is excited and emits light, and electricity is converted into light energy. The emission does not create heat; thus, it is also called "cold light." This type of emission, which uses the electron transition between valence and conduction bands or the collision of high energy electrons with the activator inside a phosphor layer and the luminescent center to excite and emit energy, is different from an LED, which employs the recombination of the electron-hole pair near the p-n junction to emit light. Because the TDEL structures have the advantages of being large-size, low-cost, and non-heat-producing and produce 


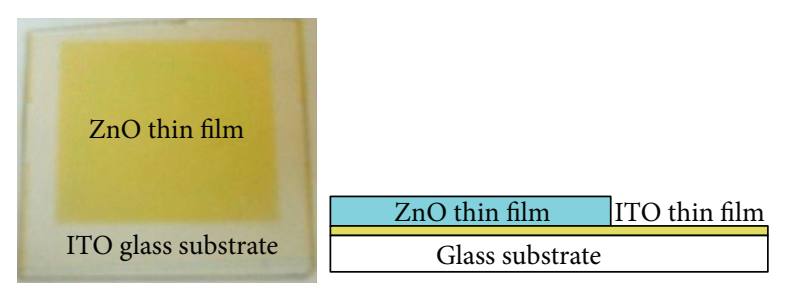

FIGURE 1: The $\mathrm{ZnO}$ thin film sample and structure schematic drawing.

uniform emission, they are suitable as fully solidified, largesize emission products, and have great developmental potential for future lighting equipment as an alternative to LCD backlights.

Because $\mathrm{ZnO}$ demonstrates abundant sources, low prices, nontoxic characteristics, radiation resistance, high temperature resistance, and chemical stability, it has become an extremely important photoelectric thin film material. Common $\mathrm{ZnO}$ thin film production methods include spray pyrolysis [1], metal organic chemical vapor deposition [2, 3], sputtering methods [4-6], thermal oxidation [7], and sol-gel methods [8-10]. Because the sputtering method is nonpolluting and exhibits superior thin film adhesion, flexibility in changing the partial pressure ratio of reactive gases, and stoichiometric qualities that effectively control thin film growth, it is currently the most commonly studied $\mathrm{ZnO}$ thin film preparation method.

Because $\mathrm{ZnO}$ at room temperature has an optical band gap of $3.3 \mathrm{eV}$ and an extremely large exciton binding energy of $60 \mathrm{meV}$ [11-13], it can potentially be used as an ultraviolet (UV) light source. This study focuses on the exploration of the fluorescent material $\mathrm{ZnO}: \mathrm{Zn}$, which is known for its high efficiency and low voltage excitation. To avoid contamination by impurities of traditional electrophoretic deposition or screen printing, which decreases the fluorescent material's emitted luminosity and lifespan, radio frequency (RF) sputtering was employed at room temperature to deposit $\mathrm{ZnO}$ thin film ( $\mathrm{ZnO}: \mathrm{Zn})$. The exploration of the $\mathrm{ZnO}$ thin film's internal structure and changes in UV emission properties were conducted by changing thermal annealing procedural parameters.

\section{Experimental Procedure}

This study employed RF sputtering to deposit a $\mathrm{ZnO}: \mathrm{Zn}$ thin film on an indium tin oxide (ITO) glass substrate at room temperature. Different thermal annealing parameters were used to explore changes in the thin film's structural organization and constituent properties and how these changes influence the $\mathrm{ZnO}$ thin film's UV emission properties. Prior to the experiment, the substrate was ultrasonically cleaned with acetone, isopropanol, and deionized water separately for $30 \mathrm{~min}$ and then dried. A sputtering system was then employed to deposit a $\mathrm{ZnO}$ thin film on the substrate. This experiment used a $99.99 \%$ pure $\mathrm{Zn}$ target and introduced oxygen $\left(\mathrm{O}_{2}\right)$ and argon (Ar) during the preparation process as the reactive gases for sputtering. The sputtering parameters comprised a fixed sputtering power of $100 \mathrm{~W}, 30 \% \mathrm{O}_{2}$ concentration, sputtering pressure of $5 \times 10^{-3}$ torr, and a deposition time of $30 \mathrm{~min}$. The completed $\mathrm{ZnO}$ thin film sample is as shown in Figure 1.

After deposition, the $\mathrm{ZnO}$ thin film was placed in a high-temperature furnace under atmospheric conditions. A $10^{\circ} \mathrm{C} / \mathrm{min}$ temperature heating rate was used to raise the temperature to $300^{\circ} \mathrm{C}, 400^{\circ} \mathrm{C}, 500^{\circ} \mathrm{C}$, and $600^{\circ} \mathrm{C}$ for thermal annealing. A dwelling time of $15 \mathrm{~min}, 30 \mathrm{~min}, 45 \mathrm{~min}$, and $60 \mathrm{~min}$ was adopted in the experiment. These analyses were employed for an in-depth exploration of how different thermal annealing parameters affected the $\mathrm{ZnO}$ thin film's internal structure and UV emission properties.

\section{Results and Discussion}

Figure 2 is an SEM surface and cross section topographical image of a $\mathrm{ZnO}$ thin film without thermal annealing. The image clearly shows that the surface of the as-deposited $\mathrm{ZnO}$ thin film is flat, the thin film's internal structure is loose, and crystals did not grow significantly. This is because the low $-\mathrm{O}_{2}$, low-pressure sputtering environment created by the $30 \% \mathrm{O}_{2}$ concentration and $5 \times 10^{-3}$ torr sputtering pressure caused the thin film deposition rate to accelerate, and because the rapid stacking of the atoms easily caused the thin film's interior to exhibit an amorphous morphology of small particle accumulation.

Figure 3 shows the XRD diffraction analysis of the asdeposited $\mathrm{ZnO}$ thin film. These results reveal that not only the $\mathrm{ZnO}$ peaks but also a $\mathrm{Zn}$ (101) peak. This is because $\mathrm{O}_{2}$ (atomic weight: 15.999) is a lighter particle, and in the low-pressure sputtering environment, an $\mathrm{O}_{2}$ atmosphere can easily be pulled out, leaving a higher quantity of the heavier Ar gas (atomic weight: 39.948). An insufficient $\mathrm{O}_{2}$ concentration in the chamber not only increases the rate of thin film deposition but also causes the sputtered $\mathrm{Zn}$ atoms to form a $\mathrm{ZnO}$ thin film with a high $\mathrm{Zn}$ content $(\mathrm{ZnO}: \mathrm{Zn})$ [14] because of insufficient oxidization. This result can be confirmed through an EDS analysis (Figure 4). The figure shows a significant difference in $\mathrm{Zn}: \mathrm{O}_{2}$ ratio, which indicates that low- $\mathrm{O}_{2}$, low-pressure sputtering can easily lead to a higher $\mathrm{Zn}$ content in the $\mathrm{ZnO}$ thin film.

Figures 5(a), 5(b), 5(c), and 5(d) are SEM topographical profiles for thermal annealing at $300^{\circ} \mathrm{C}, 400^{\circ} \mathrm{C}, 500^{\circ} \mathrm{C}$, and $600^{\circ} \mathrm{C}$, under atmospheric conditions, and for $30 \mathrm{~min}$. The images clearly show that the thin film thickness increased with an increase in thermal annealing temperature. The crystals in the thin film also show a tendency to increase in size. When the $\mathrm{ZnO}$ thin film $(\mathrm{ZnO}: \mathrm{Zn})$ prepared in the 

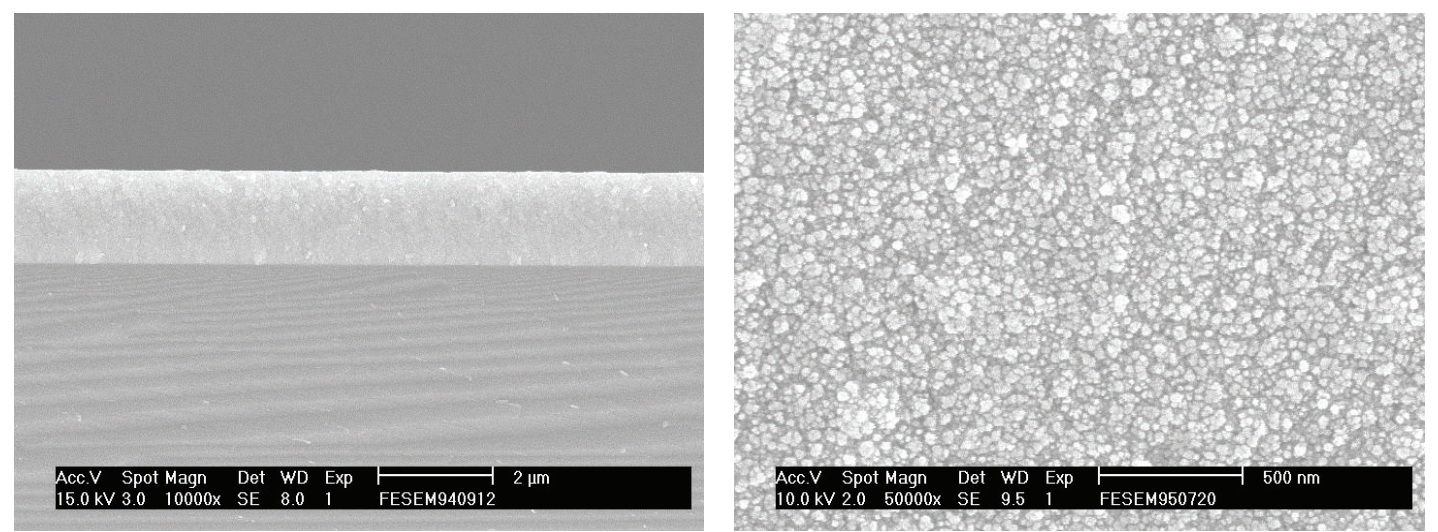

FIGURE 2: SEM surface and cross section topographical image of the as-deposited $\mathrm{ZnO}$ thin film.

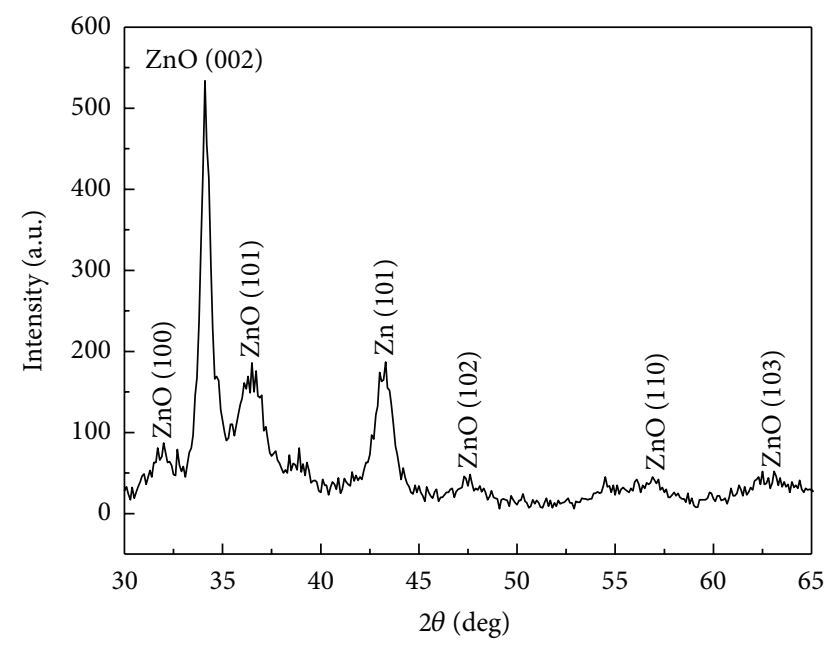

Figure 3: XRD diffraction analysis of the as-deposited $\mathrm{ZnO}$ thin film.

experiment was thermally annealed at $300^{\circ} \mathrm{C}$, it exhibited a morphology of small particle accumulation in the internal structure because of the low temperature that resulted in limited reaction of the excess $\mathrm{Zn}$. This was similar to the $\mathrm{ZnO}$ thin film structure that has not been thermally annealed. When the thermal annealing temperature increased to $400^{\circ} \mathrm{C}$, the thin film's internal structure began to exhibit a molten state. When the thermal annealing temperature approached the $\mathrm{Zn}$ melting point $\left(419.58^{\circ} \mathrm{C}\right)$, a portion of the excess $\mathrm{Zn}$ in the thin film melted. At a $500^{\circ} \mathrm{C}$ thermal annealing temperature, the thin film's internal crystal growth was significant and exhibited many holes because the high-temperature thermal annealing caused the $\mathrm{Zn}$ in the thin film to dissipate. When thermal annealing temperature reached $600^{\circ} \mathrm{C}$, because the temperature was higher, not only was the crystal growth more apparent, but the $\mathrm{Zn}$ dissipation was also more severe, resulting in a greater number of holes.

Figure 6 is the PL spectrogram for different thermal annealing temperatures, where the excitation light source was a $325 \mathrm{~nm}$ wavelength helium-neon laser. The testing parameters ranged between $350 \mathrm{~nm}$ and $620 \mathrm{~nm}$. The testing

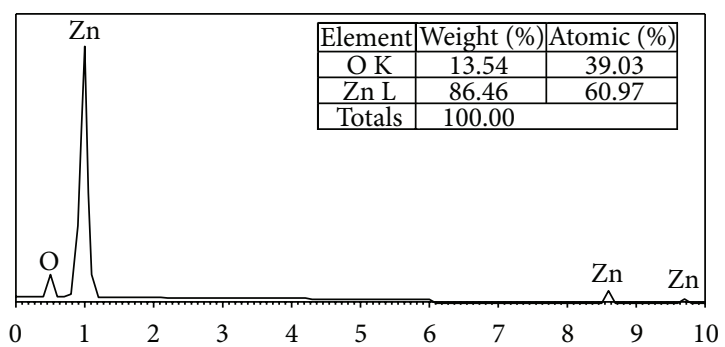

Figure 4: EDS analysis of the as-deposited $\mathrm{ZnO}$ thin film.

results showed that the UV emission center was located approximately at the $376 \mathrm{~nm}$ wavelength. By using the emitting wavelength and band gap conversion formula (1), the calculations clarified that after thermal annealing; the $\mathrm{ZnO}$ thin film prepared in this experiment had a band gap of approximately $3.3 \mathrm{eV}$. Consider

$$
\alpha h v=A\left(h v-E_{g}\right)^{n} .
$$

In addition, with an increase in the thermal annealing temperature, the PL intensity showed an increasing trend. However, when the temperature reached $600^{\circ} \mathrm{C}$, a $523 \mathrm{~nm}$ visible light (green) emission peak appeared simultaneously. Because $\mathrm{ZnO}$ materials can concurrently possess visible and invisible light (UV) emission properties, after discounting the self-emitting UV, the visible light emission is considered to result from an internal thin film defect, which is caused by electrons colliding with the luminescent center under high voltages. Vanheusden et al. [15-17] asserted that the green light's luminescent center, which is situated between $510 \mathrm{~nm}$ and $525 \mathrm{~nm}$, is related to an $\mathrm{O}_{2}$ vacancy $\left(V_{O}\right)$. According to their experimental results, high-temperature annealing consumes large quantities of $\mathrm{O}_{2}$ in the air, increasing $V_{O}$ in the thin film and subsequently caused the intensity of the green light emission to increase. The experimental results in this study exhibit the same emission trend. Thus, it is inferred that the reduction of UV emission intensity and the appearance of a green light emission peak in the $\mathrm{ZnO}$ thin film are related to high-temperature thermal annealing, which generated internal thin film defects. 


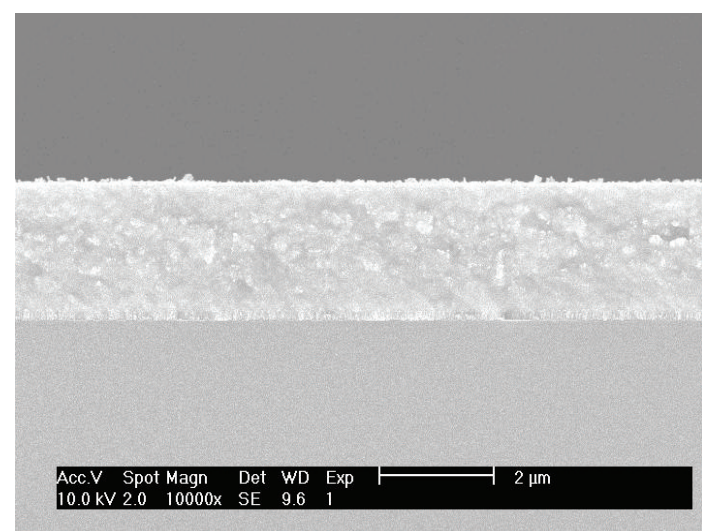

(a)

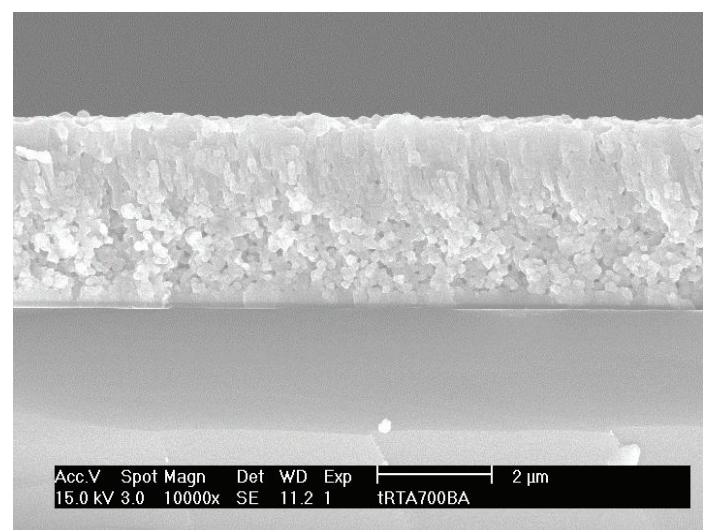

(c)

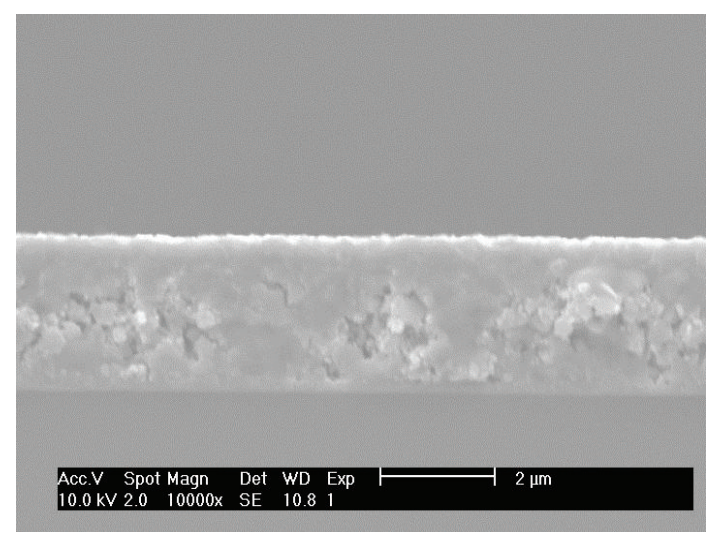

(b)

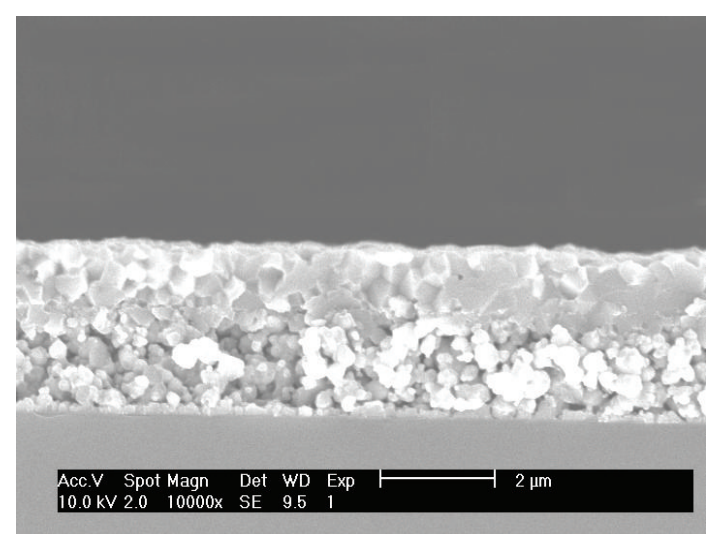

(d)

FIGURE 5: SEM cross section morphologies of $\mathrm{ZnO}$ thin film annealing under different temperatures: (a) $300^{\circ} \mathrm{C}$, (b) $400^{\circ} \mathrm{C}$, (c) $500^{\circ} \mathrm{C}$, and (d) $600^{\circ} \mathrm{C}$.

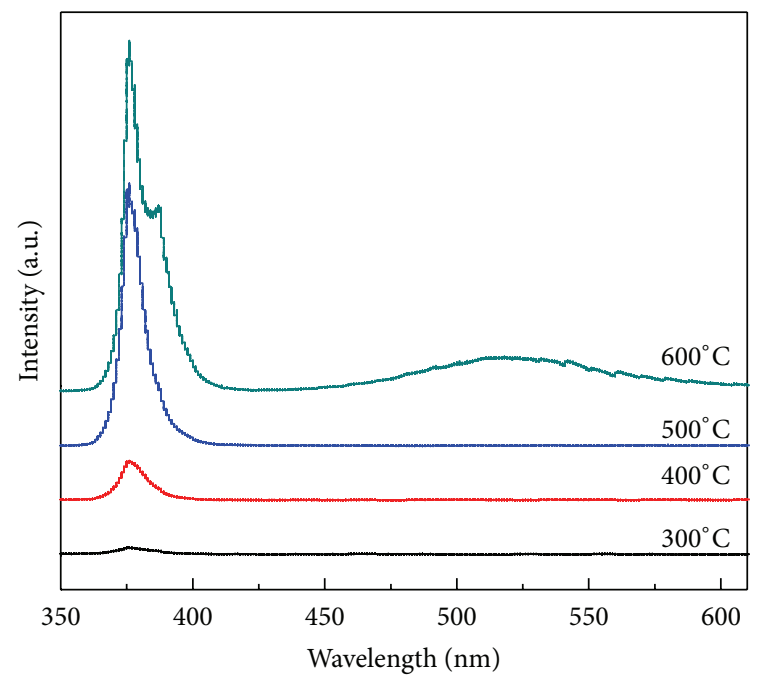

FIGURE 6: PL spectra of $\mathrm{ZnO}$ thin film annealing under different temperatures (dwelling time: $30 \mathrm{~min}$ ).

Because the change in the UV emission intensity is related to the crystallization of the thin film during thermal annealing, this experiment conducted an XRD measurement

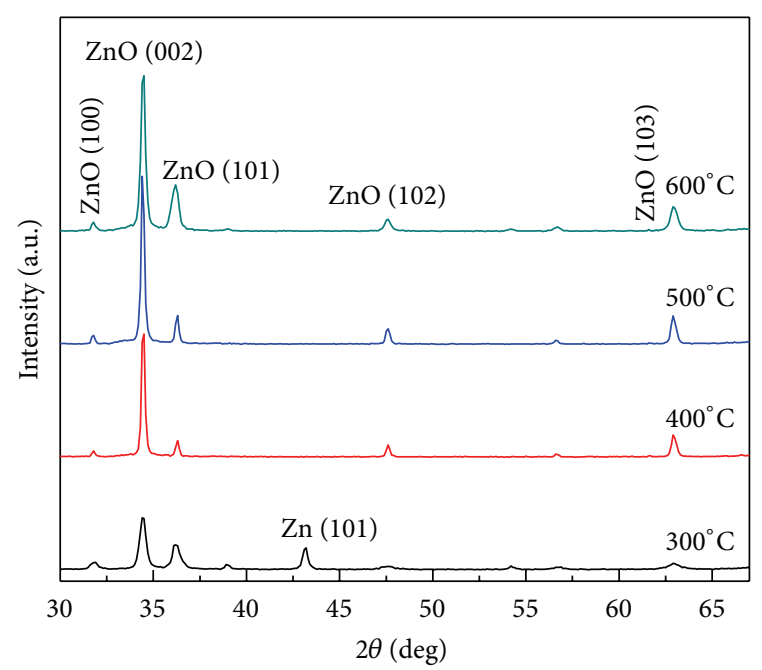

FIGURE 7: XRD diffraction peaks of $\mathrm{ZnO}$ thin film annealing under different temperatures.

analysis to discover how they could be linked. The XRD diffraction analysis diagram for different thermal annealing temperatures (Figure 7) clearly shows that with an increase 


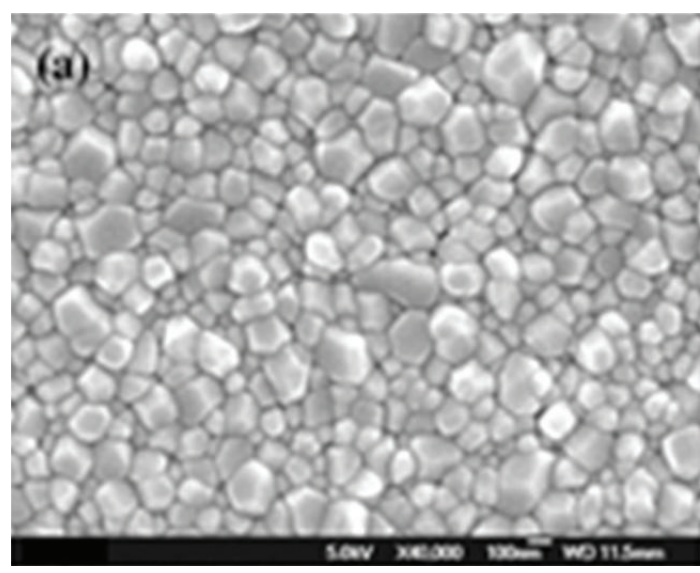

(a)

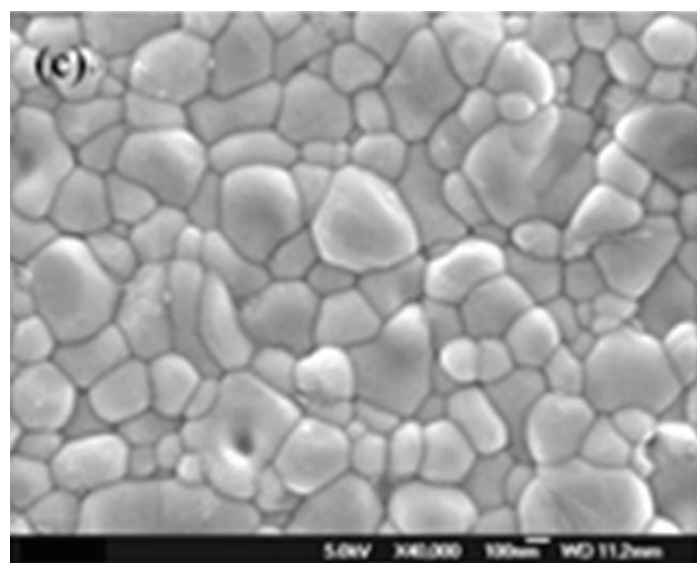

(c)

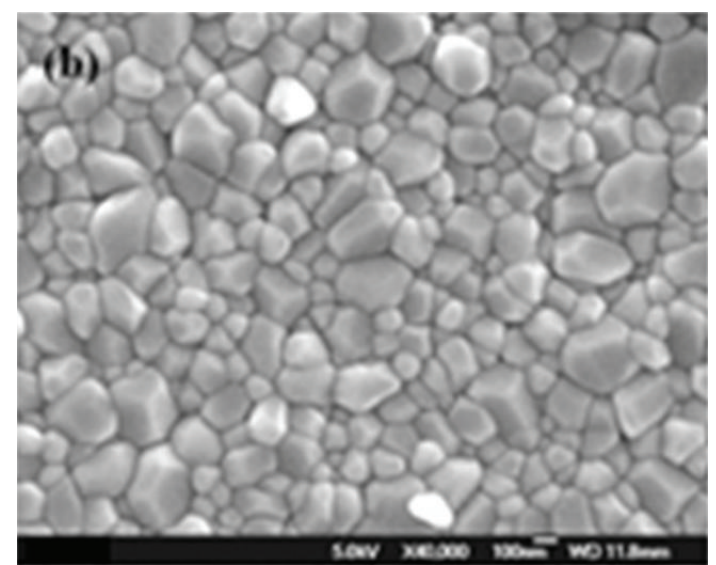

(b)

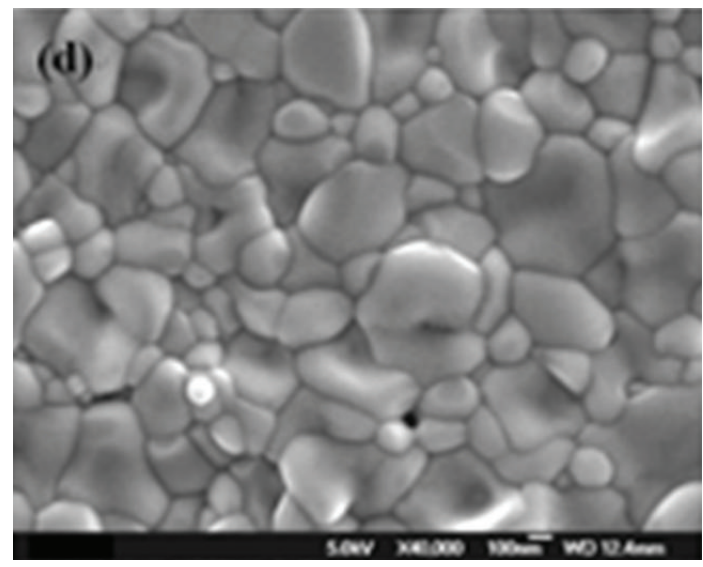

(d)

FIGURE 8: SEM surface morphologies of $\mathrm{ZnO}$ thin film annealing under different dwelling time: (a) $15 \mathrm{~min}$, (b) $30 \mathrm{~min}$, (c) $45 \mathrm{~min}$, and (d) $60 \mathrm{~min}$.

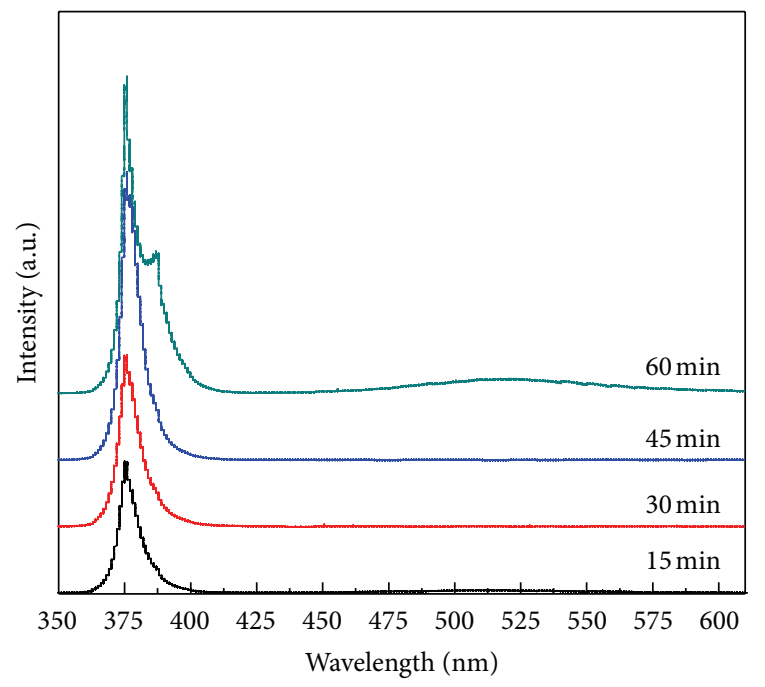

FIGURE 9: PL spectra of $\mathrm{ZnO}$ thin film annealing under different dwelling time (annealing temperature: $500^{\circ} \mathrm{C}$ ).

in thermal annealing temperature, $\mathrm{ZnO}(002)$ exhibited an increasing degree of preferred $C$-axis orientation. This indicates that high-temperature thermal annealing can improve crystallization in the $\mathrm{ZnO}$ thin film. However, after $300^{\circ} \mathrm{C}$ thermal annealing of the $\mathrm{ZnO}$ thin film, the image not only showed crystalline phase peak of $\mathrm{ZnO}(002)$ and $\mathrm{ZnO}$ (101) but also showed a diffraction peak of $\mathrm{Zn}$ (101). This is because the $300^{\circ} \mathrm{C}$ thermal annealing temperature had not reached the melting point of $\mathrm{Zn}$; thus, the excess $\mathrm{Zn}$ in the thin film could not completely react. By increasing the thermal annealing temperature, the $C$-axis orientation of $\mathrm{ZnO}$ gradually increased. However, the peaks of other $\mathrm{ZnO}$ phases also progressively increased. When the temperature reached $600^{\circ} \mathrm{C}$, the $C$-axis orientation began to reduce. Conversely, the increases in the $\mathrm{ZnO}$ (101), (102), and (103) peaks became more significant. This is because the $\mathrm{ZnO}$ thin film prepared in this experiment contained more $\mathrm{Zn}$, and the $\mathrm{Zn}$ recombined with the $\mathrm{O}_{2}$ in the air during thermal annealing, forming $\mathrm{ZnO}$. The $\mathrm{ZnO}$ crystals with poor crystallization then formed in various directions, thus exhibiting a $\mathrm{ZnO}$ thin film structure with polycrystal patterns.

Figure 8 shows the SEM surface images of the thin film at a fixed thermal annealing temperature of $500^{\circ} \mathrm{C}$, under atmospheric conditions, and for $15 \mathrm{~min}, 30 \mathrm{~min}, 45 \mathrm{~min}$, and $60 \mathrm{~min}$. The figure shows that the length of dwelling time affected the crystal growth. A longer dwelling time provides more reaction time and thermal energy that is required for 

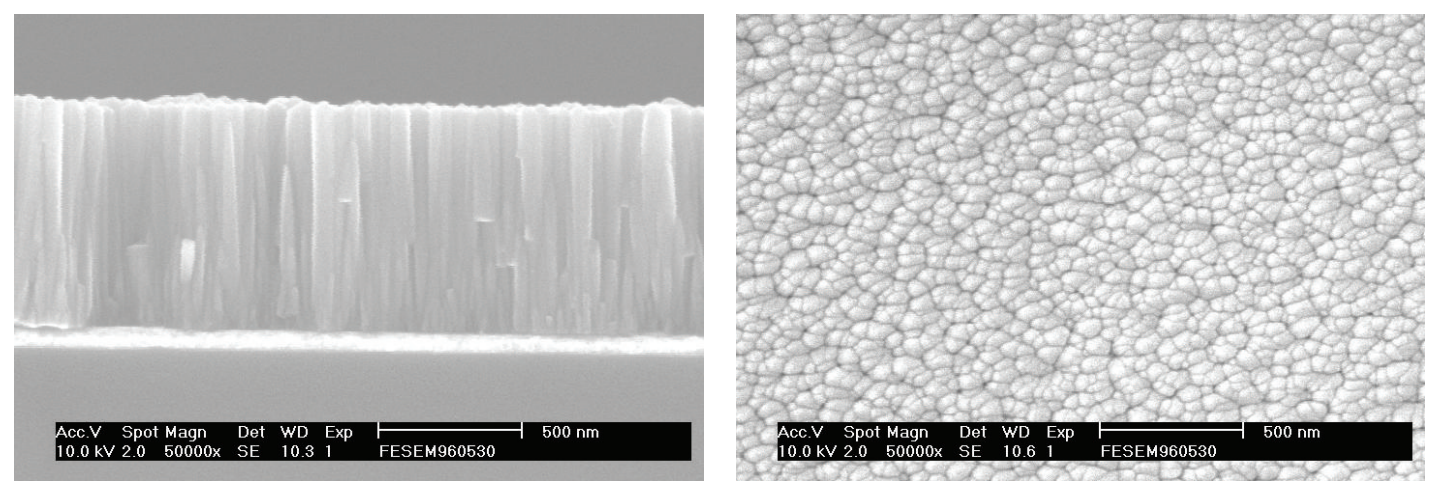

FIGURE 10: SEM surface and cross section topographical images of the $\mathrm{ZnO}$ thin film deposited on low- $\mathrm{O}_{2}$ and low-pressure sputtering environment.

crystal growth and recrystallization. Therefore, the crystal size increases with an increase in the dwelling time. After maintaining the temperature for $45 \mathrm{~min}$, the resulting crystal morphology appeared similar to that for $60 \mathrm{~min}$. The primary reason is that the excess $\mathrm{Zn}$ in the thin film has almost completely reacted with the $\mathrm{O}_{2}$ in the air and formed $\mathrm{ZnO}$; consequently, the $\mathrm{Zn}$ source for recrystallization was reduced, leading to decelerated crystal growth.

Figure 9 is the PL spectrogram for different dwelling times. In the figure, the UV emission intensity increased as the dwelling time was extended. The size of the crystals and the intensity of the UV emission were positively correlated. However, when the dwelling time reached $60 \mathrm{~min}$, the PL image also began to show the emission peak of visible light (green). This indicates that thermal annealing not only allowed the crystals to grow and improved the thin film's internal crystallization but also highlighted the existing defects in the thin film with an increase in the dwelling time. Consequently, the PL image produced a visible light emission peak.

Figure 10 is the SEM surface and cross section topographical images of the $\mathrm{ZnO}$ thin film by $60 \% \mathrm{O}_{2}$ concentration and $20 \times 10^{-3}$ torr sputtering pressure, under atmospheric conditions. The image clearly shows that the surface of the $\mathrm{ZnO}$ thin film is flat; the thin film's internal structure is dense, because sufficient $\mathrm{O}_{2}$ concentration in the environment induced the thin film deposition rate to retard and exhibit a well hexagonal wurtzite structure.

Figure 11 is the XRD diffraction analysis diagram of $\mathrm{ZnO}$ thin film. It can be observed from Figure 11, it exhibited only the $\mathrm{ZnO}(002)$ peak. This is because the high- $\mathrm{O}_{2}$, high-pressure sputtering environment caused the zinc ion completely oxidized, to be increased the thin film's internal crystallization. Figure 12 is the PL spectrogram of $\mathrm{ZnO}$ thin film. The results showed only a weak $376 \mathrm{~nm}$ UV emission peak without the other visible light peak.

$\mathrm{ZnO}$ thin films with thermal annealing at $500^{\circ} \mathrm{C}$ (for $45 \mathrm{~min}$ ) and atmospheric conditions exhibited a sharp (002) peak and small value of FWHM (full width at half maximum), as shown in Figure 13. Figure 14 presents the PL spectrogram for $\mathrm{ZnO}$ thin films with thermal annealing processes. The results shows a more obvious $376 \mathrm{~nm}$ UV emission peak

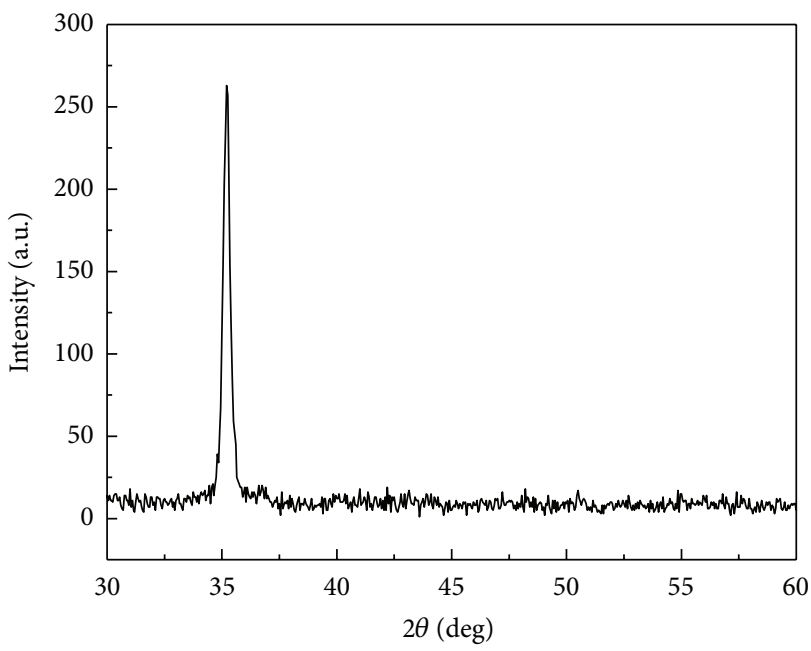

FIGURE 11: XRD diffraction analysis of the $\mathrm{ZnO}$ thin film deposited on low- $\mathrm{O}_{2}$ and low-pressure sputtering environment.

because the thermal annealing processes increase the internal grain size of $\mathrm{ZnO}$ thin films.

\section{Conclusion}

This study employed RF sputtering at room temperature to deposit a $\mathrm{ZnO}$ thin film on an ITO glass substrate. By varying the thermal annealing temperatures and dwelling times, this study explored changes in the thin film's internal structure and UV emission properties. The results showed that a low$\mathrm{O}_{2}$, low-pressure sputtering environment readily forms a $\mathrm{ZnO}$ thin film with high $\mathrm{Zn}$ content. The excess $\mathrm{Zn}$ exhibited influences of differing levels on crystal growth and emission properties when different thermal annealing parameters were applied. The experiment showed that an increase in thermal annealing temperature or dwelling time resulted in gradual growth of crystal size, and when specific parameters were applied, the UV emission intensity increased with the crystal growth. However, when the thermal annealing temperature was at $600^{\circ} \mathrm{C}$ or when the dwelling time reached $60 \mathrm{~min}$, 


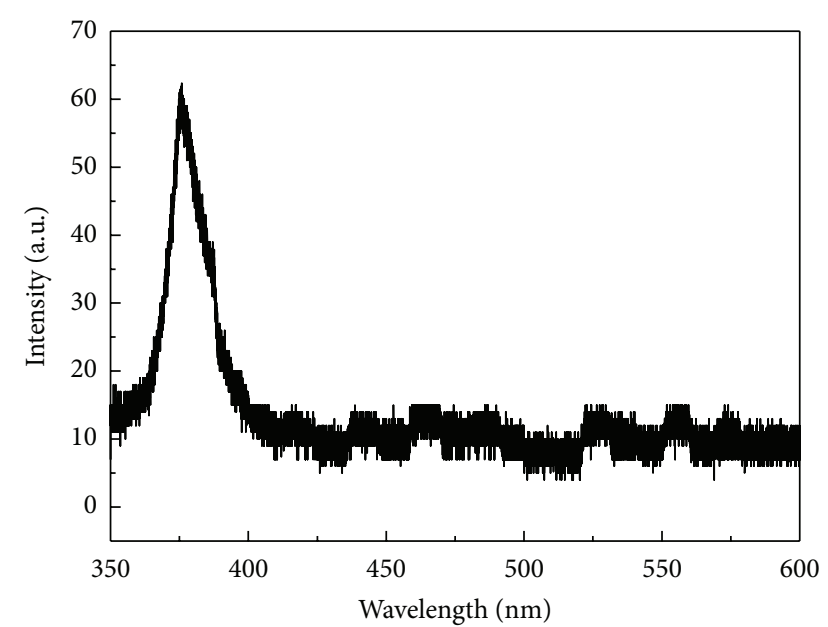

Figure 12: PL spectra of $\mathrm{ZnO}$ thin film deposited on low- $\mathrm{O}_{2}$ and low-pressure sputtering environment.

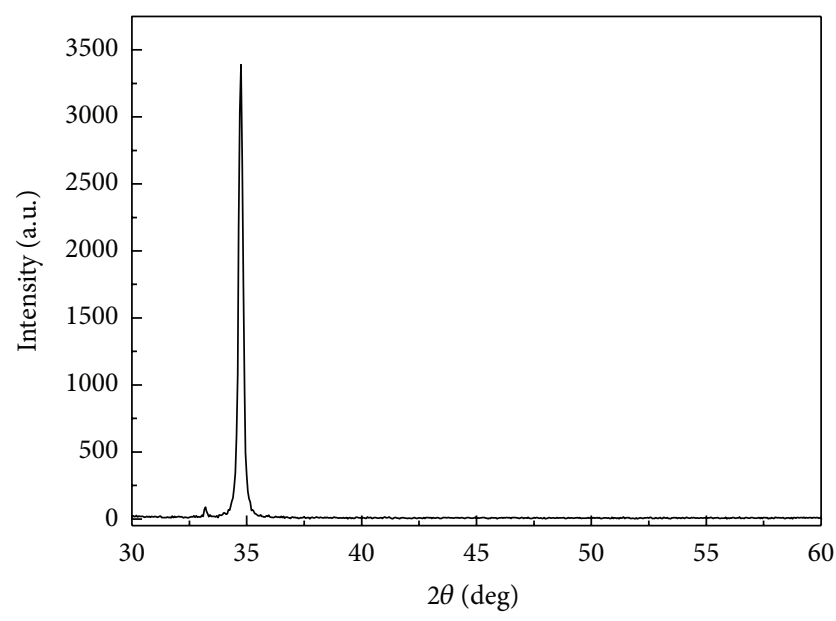

FIGURE 13: XRD diffraction analysis of the $\mathrm{ZnO}$ thin film deposited on low- $\mathrm{O}_{2}$ and low-pressure sputtering environment with thermal annealing process.

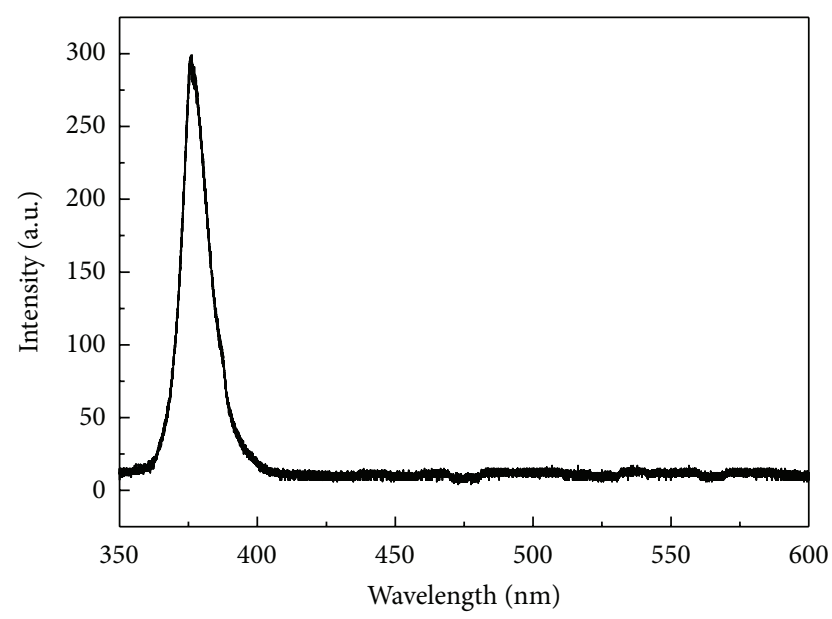

Figure 14: PL spectra of $\mathrm{ZnO}$ thin film deposited on low- $\mathrm{O}_{2}$ and low-pressure sputtering environment with thermal annealing process. actually exhibited a weak green light emission peak. This indicates that the thermal annealing process increased the thin film's internal crystallization and simultaneously enhanced the defects in the thin film and the growth of other crystalline phases. This is evidenced by the PL spectrogram and XRD diffraction analysis results. Consequently, $\mathrm{ZnO}$ luminescence is a type of defective emission caused by the $V_{O}$ in the thin film. Thus, the width of $\mathrm{ZnO}$ band gap determines the wavelength position of the UV emission center, and the grain size dominates the intensity of UV emission. In order to obtain the well UV emission, the $\mathrm{Zn}: \mathrm{O}_{2}$ ratio must be controlled with thermal annealing processes to improve the crystallization and grain size.

\section{References}

[1] U. Alver, T. Kilinç, E. Bacaksiz, and S. Nezir, "Temperature dependence of $\mathrm{ZnO}$ rods produced by ultrasonic spray pyrolysis method," Materials Chemistry and Physics, vol. 106, no. 2-3, pp. 227-230, 2007.

[2] J. Ye, S. Gu, S. Zhu et al., "The growth and annealing of single crystalline $\mathrm{ZnO}$ films by low-pressure MOCVD," Journal of Crystal Growth, vol. 243, no. 1, pp. 151-156, 2002.

[3] Z. Fu, B. Lin, and J. Zu, "Photoluminescence and structure of $\mathrm{ZnO}$ films deposited on Si substrates by metal-organic chemical vapor deposition," Thin Solid Films, vol. 402, no. 1-2, pp. 302306, 2002.

[4] Q. P. Wang, D. H. Zhang, Z. Y. Xue, and X. J. Zhang, "Mechanisms of green emission from $\mathrm{ZnO}$ films prepared by rf magnetron sputtering," Optical Materials, vol. 26, no. 1, pp. 23-26, 2004.

[5] W. Lin, R. Ma, W. Shao, B. Kang, and Z. Wu, "Properties of doped $\mathrm{ZnO}$ transparent conductive thin films deposited by RF magnetron sputtering using a series of high quality ceramic targets," Rare Metals, vol. 27, no. 1, pp. 32-35, 2008.

[6] D. Kim, T. Shimomura, S. Wakaiki, T. Terashita, and M. Nakayama, "Photoluminescence properties of high-quality $\mathrm{ZnO}$ thin films prepared by an RF-magnetron sputtering method," Physica B, vol. 376-377, no. 1, pp. 741-744, 2006.

[7] S. H. Bae, S. Y. Lee, H. Y. Kim, and S. Im, "Effects of postannealing treatment on the light emission properties of $\mathrm{ZnO}$ thin films on Si," Optical Materials, vol. 17, no. 1-2, pp. 327-330, 2001.

[8] P. T. Hsieh, Y. C. Chen, K. S. Kao, M. S. Lee, and C. C. Cheng, "The ultraviolet emission mechanism of $\mathrm{ZnO}$ thin film fabricated by sol-gel technology," Journal of the European Ceramic Society, vol. 27, no. 13-15, pp. 3815-3818, 2007.

[9] S. Hwangbo, Y.-J. Lee, and K.-S. Hwang, "Photoluminescence of $\mathrm{ZnO}$ layer on commercial glass substrate prepared by sol-gel process," Journal of Crystal Growth, vol. 290, pp. 341-344, 2006.

[10] P. Sagar, P. K. Shishodia, R. M. Mehra, H. Okada, A. Wakahara, and A. Yoshida, "Photoluminescence and absorption in sol-gelderived $\mathrm{ZnO}$ films," Journal of Luminescence, vol. 126, no. 2, pp. 800-806, 2007.

[11] S. J. Pearton, D. P. Norton, K. Ip, Y. W. Heo, and T. Steiner, "Recent advances in processing of ZnO," Journal of Vacuum Science and Technology B, vol. 22, no. 3, pp. 932-948, 2004.

[12] F. Bertram, D. Forster, J. Christen, N. Oleynik, A. Dadgar, and A. Krost, "Microscopic spatial distribution of bound excitons in high-quality ZnO," Journal of Crystal Growth, vol. 272, no. 1-4, pp. 785-788, 2004. 
[13] V. Srikant and D. R. Clarke, "On the optical band gap of zinc oxide," Journal of Applied Physics, vol. 83, no. 10, pp. 5447-5451, 1998.

[14] K. H. Yoon, J.-W. Choi, and D.-H. Lee, "Characteristics of $\mathrm{ZnO}$ thin films deposited onto $\mathrm{Al} / \mathrm{Si}$ substrates by r.f. magnetron sputtering," Thin Solid Films, vol. 302, no. 1-2, pp. 116-121, 1997.

[15] K. Vanheusden, W. L. Warren, C. H. Seager, D. R. Tallant, J. A. Voigt, and B. E. Gnade, "Mechanisms behind green photoluminescence in $\mathrm{ZnO}$ phosphor powders," Journal of Applied Physics, vol. 79, no. 10, pp. 7983-7990, 1996.

[16] H. S. Kang, J. S. Kang, S. S. Pang, E. S. Shim, and S. Y. Lee, "Variation of light emitting properties of $\mathrm{ZnO}$ thin films depending on post-annealing temperature," Materials Science and Engineering B, vol. 102, no. 1-3, pp. 313-316, 2003.

[17] B. Lin, Z. Fu, Y. Jia, and G. Liao, "Defect photoluminescence of undoping $\mathrm{ZnO}$ films and its dependence on annealing conditions," Journal of the Electrochemical Society, vol. 148, no. 3, pp. G110-G113, 2001. 

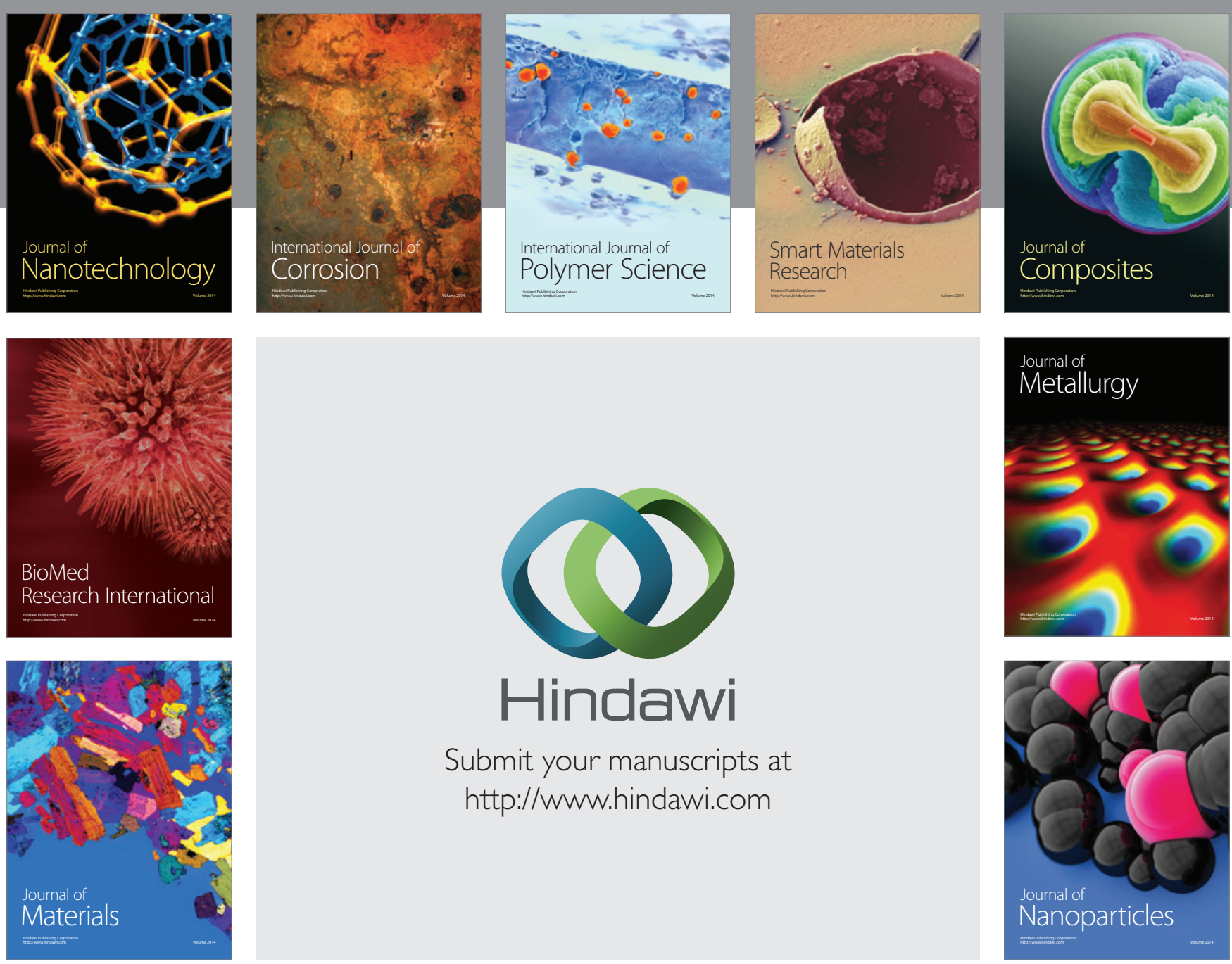

Submit your manuscripts at http://www.hindawi.com
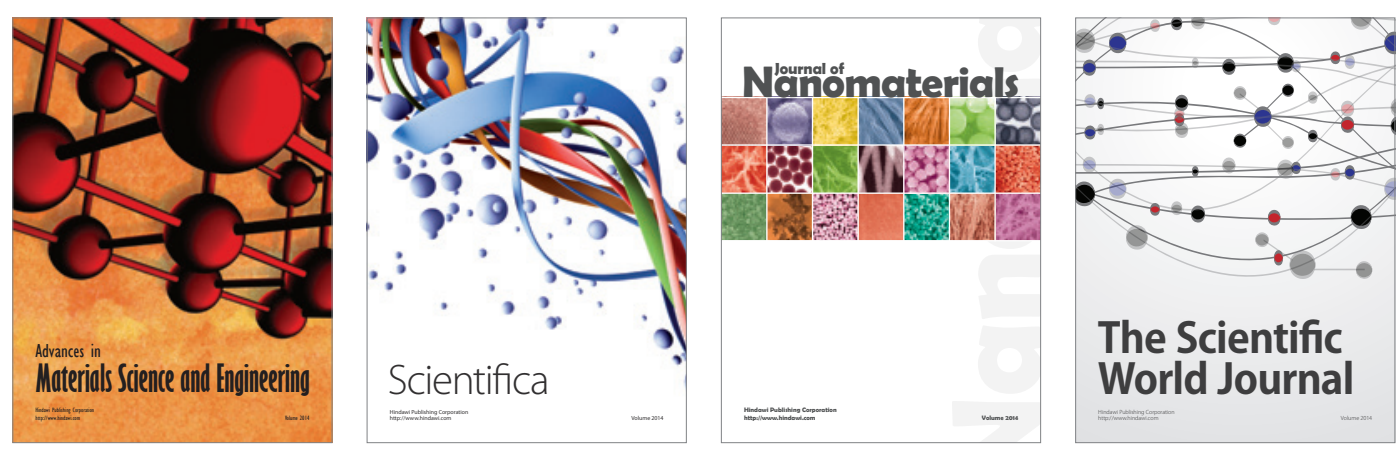

\section{The Scientific World Journal}
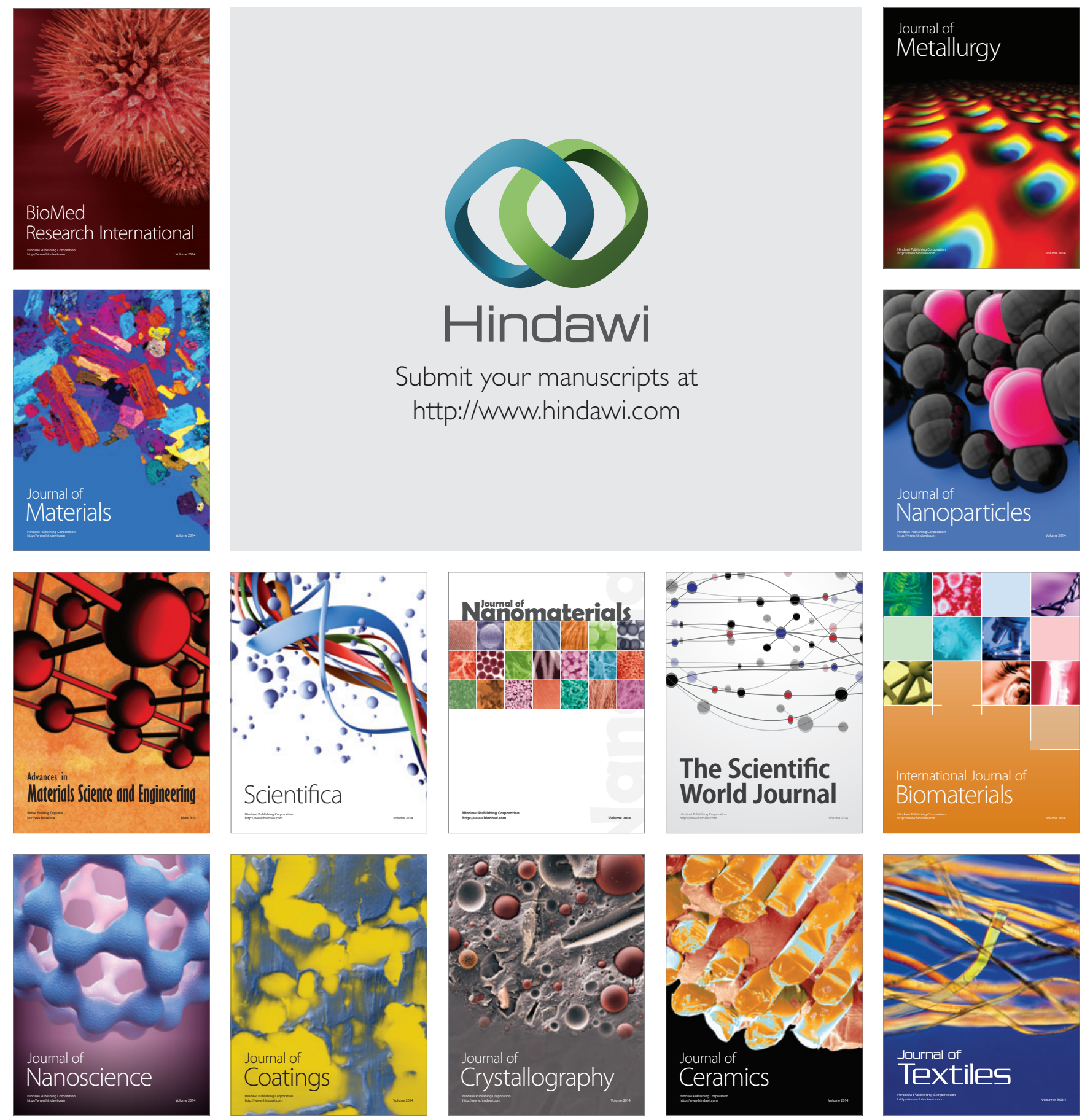